Article

\title{
Coordination of Store Brand Product's Green Supply Chain Based on Negotiation
}

\author{
Shaobo Wu ${ }^{1}$, Shiping Wen ${ }^{2, *}$, Quan Zhou ${ }^{3}$ and Xinghong Qin ${ }^{3}$ \\ 1 School of Management, Southwest University for Nationalities, Chengdu 610041, China; \\ wushaoboscu20202@126.com \\ 2 School of Economics and Management, Tongji University, Shanghai 201804, China \\ 3 Strategical Planning School, Chongqing Technology and Business University, Chongqing 400067, China; \\ cncqzq@ctbu.edu.cn (Q.Z.); qinxh@ctbu.edu.cn (X.Q.) \\ * Correspondence: 1610325@tongji.edu.cn
}

Received: 22 March 2020; Accepted: 28 April 2020; Published: 1 May 2020

\begin{abstract}
The environmental input of a store brand product's green supply chain plays an important role in improving the product brand image and expanding the product demand. According to the difference of the initial one-off environmental investment of the store brand product, it can be divided into three modes: direct OEM, retailer's full participation and retailer's partial participation. The research methods employed in this study include model establishment, numerical analysis and comparison under three entrustment modes based on retailers' negotiation strength. In addition, sensitivity analysis was used to test the influence of parameter variations on the results. The research results show that: (i) the direct OEM mode is the best choice for retailers when the retailer is in a weak position, but it is not the best choice for the manufacturer. With the increase of the retailers' negotiation strength, the profits of both sides will decline, causing the problem of double marginal profit decreasing; (ii) the retailer's full participation mode is the best choice for the manufacturer when the retailer is in a strong position, but not the best choice for the retailer. It is not the best choice for both sides when the retailer is in a weak position; (iii) the greenness and total profit of the supply chain are no relative with the negotiation strength of the retailer under the partial participation mode, and the greenness and total profit of the supply chain are the same as the condition under the integrated control to achieve the best coordination effect.
\end{abstract}

Keywords: store brand; green supply chain; negotiation; coordination; game theory

\section{Introduction}

With the rapid development of the economy and increasingly fierce competition in the market, the traditional partnership between manufacturers and retailers within the supply chain has become diversified and complicated [1]. On the one hand, many manufacturers choose direct sales channels to reduce their reliance on retailers. On the other hand, the choice of store brand ingress into the upstream supply chain by some retailers has become an important step to attract consumers and improve supply chain control. Store brand (private brand) refers to a product that a retailer designs, researches and develops, then authorizes the manufacturer to produce and process, and which is then sold at its own retail outlet or terminal using its own registered trademark [2]. The exploitation and development of the retail store brand causes the retailers to be both a manufacturer's customer and a competitor. Retailers and manufacturers are competing for marketing resources for the sake of benefit, changing the original retail supply relationship, thus increasing the possibility of win-win cooperation at the strategic level while there are also conflicting interests. In recent years, more and more retailers have launched their own store brand products. For example, Target has launched 
more than 20 store brands in the past two years. The product categories include electronic products, baby products, underwear and many other products (including Archer farms food, Smart staples, Opalhouse home decor and other products). Because these products are so popular with consumers, the retail industry avoids an overall downturn. Walmart launched its store brand product Modrn in March 2019, focusing on online furniture. In April 2019, Walmart launched its own fashion brand "George", which mainly provides clothing, home textiles, kitchenware and other commodities and has been sold online in more than 400 Walmart stores in China now. Yonghui supermarket company put 44 store brand products, including "Tianqu" rice products, on sale in the first half year of 2019. Retailers' green investment in their store brand products and green supply chain management can bring many benefits: in terms of economic benefits, they can reduce supplier consumption, save consumers costs and improve operational efficiency. In terms of brand building, they can better shape a sound image and build a good reputation. In terms of society, they can take more social responsibility and promote sustainable development of society. Therefore, the green supply chain management of retail store brand products has become an important factor affecting their development, and it may be very important to study coordination of the green supply chain of store brand products. Even though some efforts have been made to focus on the positive influence of store brands, we still have ample opportunities to understand this complex topic. Existing studies such as Berges-Sennou (2006) and Bergèset al. (2011) [3,4] proved that retail store brands have a substantial impact on the economic profits of cooperative parties but overlooked the impact of retailer's negotiation strength on the overall supply chain performance. Therefore, it is necessary to discuss the influence of retailers' negotiation strength on supply chain stakeholders.

Negotiation strength seems to be critical for supply chain coordination, e.g., for vertical cooperative promotion contract terms such as price (e.g., Wang et al., 2014) [5]. The sources of negotiation strength are also known to be part of the bargaining process. Many existing studies have acknowledged the role of negotiation strength in supply chains. For example, Ingene and Parry (1995) [6] point out that cooperative profit should be distributed by the mechanism of negotiation in the supply chain. Choi (1991) [7] studied vertical interactions including the Vertical Nash game and Stackelberg leader-follower games in the supply chain; their research results showed that negotiation strength would result in different profit for cooperative parties. Krishnand and Soni (1997) [8] studied the "guarantee of margins" contract between the manufacture and the retailer, and their research showed that shifts in the retailer's bargaining power could affect its profit. Bernstein and Nagarajan (2011) [9] used Nash bargaining theory to study channel structure and power; in their model, wholesale price is the outcome of negotiation strength. Although Choi (1991) and Bernstein and Nagarajan (2011) emphasized that negotiation strength of retailer can optimize the price and supply chain profit, they failed to clarify the impact of negotiation strength on the greenness of products and even on the overall social and environmental performance. Therefore, the connection between retailers' negotiation strength shift and greenness of products remains unclear. The research of this paper can fill in the gaps in the previous studies above. Though some efforts have been made focusing on management systems, for example, ISO 14001, which have turned out to be useful in sustainable supply chain management $[10,11]$. As a member of society, enterprises should take the corresponding social responsibility and actively abide by these green supply chain management systems regardless of whether these systems will have an obvious impact [12]. Hence, the implementation of corporate social responsibility (CSR) in supply chains seems to be important. CSR issues include the interests of various stakeholder groups, consumers, local communities, and the natural environment [13]. In general, whether manufacturers or retailers, taking into account the greenness of products and their impact on society and the environment while obtaining profits, will help to improve their own attractiveness and credibility, thus resulting in higher competitiveness in the same industry and realizing the sustainable development of the green supply chain. Based on the above studies, we attempt to analyze how the relative negotiation strength of the retailer affects the greenness and cooperative parties' profit in the store brand product's green supply chain. Specifically, this study will mainly investigate the following questions: (i) under 
different entrusted production modes, what effect does the retailer's relative negotiation strength have on product greenness, retailer profit, manufacturer profit and total supply chain profit? (ii) Which mode can achieve the optimal coordination mode of green supply chain among the three different entrusted production modes? After clarifying the specific research problems, this study first used game theory and related mathematical methods to put forward propositions, built theoretical models and prove them to acquire the optimum solution. Secondly, MATLAB 2018a software was used to carry out simulation and numerical analysis and draw images of the profit and greenness under different entrusted production modes for comparative study, so as to make the results clearer. Finally, we adopted Excel components to analyze the sensitivity of parameters, and then drew conclusions and discuss in detail according to different modes.

The theoretical significance of this research is mainly embodied in the following aspects: (1) Since there is little literature that introduces the retailer's the shift of negotiation strength into the decision-making research of green supply chain with subsidy, this study enriches the research content about green supply chain optimal decision problem. (2) This study reveals the retailer's negotiation strength on the optimal product greenness decision and the total profit of green supply chain under the impact mechanism of the three different entrusted production modes, and presents a sensitivity analysis of parameter variations on equilibrium solutions in the context of subsidy.

The practical value of our research is mainly embodied in the following aspects: (1) this study explores the impact of the three different entrusted production modes of store brand products, which are real and significant on the optimal strategies and green supply chain members' profit; the subject of this study is closely related to the real background and has practical significance. (2) The research conclusions can not only provide reference for the stakeholders (i.e., manufactures and retailers) in a green supply chain to adopt reasonable strategies when dealing with each other's different negotiation strength, but can provide some theoretical support for the superiority side to determine the appropriate subsidy intensity for the weak side in the green supply chain through using Nash Negotiation model.

The rest of this paper is organized as follows: Section 2 is a literature review, Section 3 describes the problems for research, Section 4 establishes the basic model, Section 5 studies the green supply chain coordination under different production modes, Section 6 analyzes and compares different entrusted production modes, Section 7 is the numerical example and sensitivity analysis, Section 8 indicates the research results and discussions, and the last part is draws a conclusion and presents limitations.

\section{Literature Review}

In this section, this study investigates two categories literature regarding supply chain management on the basis of the research content of this research. One stream is research store brands, which ranges from modes of consumption behavior to product supply chain management; another one is research related to the coordinated management of the green supply chain. The reading and analysis process of literature review is described in detail in Figure 1.

\subsection{Store Brand}

Scholars have carried out many studies on retail store brands, including the consumption behavior mode of store brands, the influence of store brands on channel competition, and the supply chain management of store brand products.

\subsubsection{The Consumption Behavior Mode of Store Brands}

Richardson et al. (1994) [14] explored the factors influencing customer evaluation of retail store brand products through empirical research, mainly including product price, packaging, etc. To attract customers, retailers usually set the price of their store brand products lower than that of similar products of other manufacturers, which leads to low evaluation of their store brand products and reduces their purchase intention. Dodd and Lindley (2003) [15] found that the factors that consumers evaluate when considering brand quality mainly depend on their overall attitude towards private brands and store 
image. Steenkamp et al. (2010) [16] believe that consumers would be willing to pay a price premium for manufacturer brand products, rather than purchase the retail store brand products, if they think there is a quality difference between their store brand and the manufacturer brand. The perceived quality gap includes product innovation, packaging innovation, price promotion and advertising. When the manufacturer's products are difficult to produce and beautifully packaged, there will be a big gap between the quality perception between the private brand and the manufacturer's brand. When store brand products are contract manufactured by well-known enterprises, the quality perception of consumers between the store brand and manufacturer's brand will be reduced. Keller et al. (2016) [17] believe that with the transformation of retail store brand products, retail store brand products are no longer looked down upon as being synonymous with low cost and low quality, and to some extent, they can become substitutes for manufacturers' brands in terms of quality. Cuneo et al. (2019) [18] subdivided brand buyers according to brand choice behavior and psychological characteristics, especially with respect to lifestyle characteristics. They distinguished four types of consumers who purchased different brand type combinations: top manufacturer brand consumers, sub manufacturer consumers, top private brand consumers, and sub private brand consumers. They recognized that there are different motivations for brand selection in each segment.

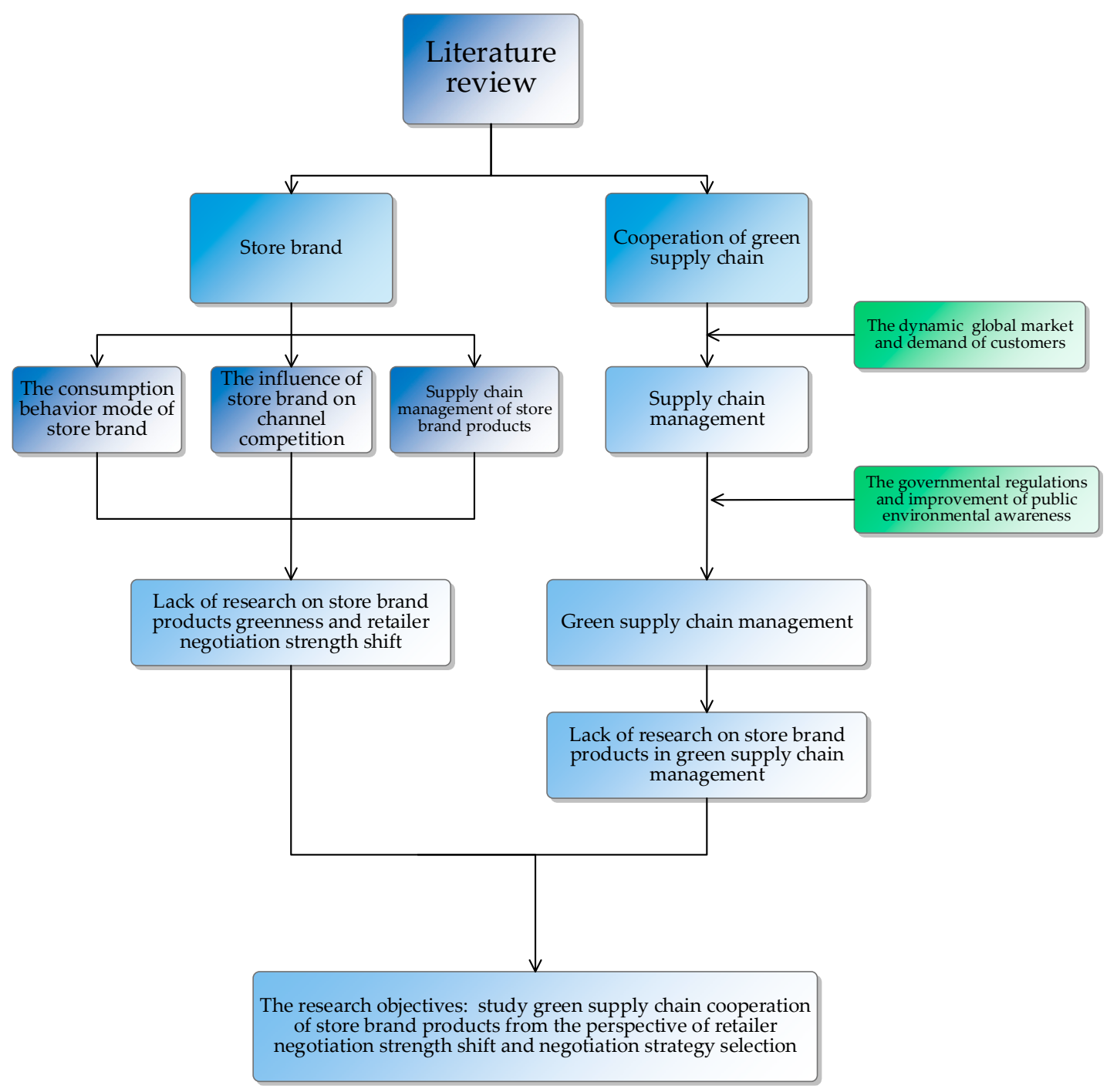

Figure 1. Research framework of literature review. 


\subsubsection{The Influence of Store Brand on Channel Competition}

Mills (1995) [19] regarded store brands as an important tool for overcoming the double marginal problems brought by manufacturer brands in the channel. He believed that retailers with certain market abilities would develop store brands to replace manufacturer brands in order to gain increased profit in the process of vertical channel sharing. If the quality gap between store brands and manufacturer brands is large, the retailer will not develop its store brand. Choi and Coughlan (2006) [20] discussed the positioning of store brands relative to manufacturer brands based on product quality and product characteristics. With respect to quality, he divided brand manufacturers into high-end strong manufacturers and low-end weak manufacturers. The research showed that the positioning of store brand products depends on the quality of their own products. When the quality of store brand products is high, it should be located in the brand competition of strong manufacturers. When the quality of the store brand is low, it should be located in the brand competition of weak manufacturers. Ru et al. (2015) [21] found that when the interaction between manufacturers and retailers was modeled as a retailer-dominated Stackelberg game, the retail store brand may be beneficial to manufacturers. This phenomenon occurs because in the established model, the retail store brand changes the nature of the strategic interaction between the manufacturer and the retailer. If the retailer does not have a store brand, its interaction with the manufacturer is always a vertical strategic alternative; if the retailer introduces a store brand, its interaction with the manufacturer may become a vertical strategic independent interaction. Therefore, with the emergence of retail store brands, the demand for the manufacturers' brands is growing, and the wholesale price of the manufacturers' brands may rise, both of which are beneficial to the manufacturer. Finally, in the Stackelberg game dominated by the retailer, store brands may alleviate the problem of dual diminishing marginal profit in the manufacturer's brand supply chain, but this is achieved in a non-traditional way: the decrease of dual diminishing marginal profit may come from the decrease of retail price increase, rather than the decrease of wholesale price. Jin et al. (2017) [22] studied the influences of different pricing schemes on channel strategies of decisions with respect to the introduction of manufacturers' and the retail brands. Under the flexible wholesale price (FWP) scheme (the manufacturer charges different price from the retailer), the motivation of the retailer to introduce a store brand in a single channel is lower than that in a dual channel. Therefore, choosing single channel could be a strategy for preventing the retailer from introducing a store brand. This strategy is effective when the retail brand has moderate competitiveness. On the contrary, under the unified wholesale price (UWP) scheme, the retailer has a lower motivation to introduce its store brands in dual channel. Li et al. (2018) [23] constructed an interactive game model between the manufacturer's channel strategy and the retailer's brand strategy. The game investigates whether the manufacturer will introduce an online direct marketing channel and whether the retailer will introduce a store brand. If the retailer has introduced a store brand, the manufacturer may introduce a direct online channel or not. It was found that if the retailer has introduced a store brand, the manufacturer may introduce an online direct marketing channel. If the retailer has not introduced a store brand, the manufacturer may not introduce the online direct marketing channel.

\subsubsection{Supply Chain Management of Store Brand Products}

Berges-Sennou (2006) [3] studied the influence of negotiation ability on whether retailers would entrust store brand production to a manufacturer. The research shows that when the manufacturer's negotiation ability is low, the retailer will entrust store brand production to the manufacturer; however, consumers' loyalty to the manufacturer's brands may change the retailer's decision-making. Bergèset al. (2011) [4] studied the production strategies of the retailer and the food manufacturer within the context of an endogenous brand quality, bargaining power, possible differences in production technology, and potential capacity constraints of the brand manufacturer, etc. They found that the retailer may prefer to choose an independent manufacturer to produce its store brand products, while the manufacturer may become the retailer's choice in cases of overcapacity. Chambolle et al. (2015) [24] studied the 
impact of the retail store brand production channel choice on innovation investment. The retailer can acquire a small enterprise to produce store brand products (business insourcing), or entrust products to a manufacturer (business outsourcing). When production is insourced, the external option effect may lead to overinvestment in innovation. When production is outsourced, the hold-up effect may lead to low investment in innovation. Ma et al. (2018) [25] studied the manufacturer's participation in the production of retail store brand products by establishing a game model. There are two ways for a retailer to produce its store brand products: marginal manufacturers with low production efficiency, or brand manufacturers with high efficiency. It was found that there is a win-win situation for brand manufacturers producing store brand products for retailers under certain conditions, and brand manufacturers providing store brand products for retailers may lead to an increased likelihood of retailers introducing store brand products. Liao et al. (2020) [26] studied the combined effect of store brand production mode and bargaining power on the quality of store brand products. The store brand production mode includes in-house manufacturing, leading national-brand manufacturers, and strategic third-party manufacturers. Considering the two forms of price leadership of the manufacturer and the retailer, they analyzed the optimal quality level and its relative value, equilibrium price, retail profit, consumer welfare and supply chain profit in six kinds of conditions.

\subsection{Cooperation of Green Supply Chain}

Supply chain management has become a vital factor in firm operations in response to dynamic demand of customers in recent decades [27,28]. To help enterprises better adapt to the dynamic global market, many scholars have performed a variety of studies on supply chain management from different perspectives [29,30]. Chatterjee and Kar (2013) [31] introduced a Fuzzy Rasch-Vikor Model to address the dynamic risky nature of the supply chain in warehouse site evaluation, meeting the needs of all customers with the minimum risk in the distribution network. Meanwhile, they developed an Interval valued fuzzy (IVF)-TOPSIS-based method for handling the supplier selection problem in an uncertain electronics supply chain [32]. However, under conditions of stricter governmental regulations and increasing public awareness of environmental protection problems, many firms are undertaking major initiatives to make their supply chains greener by enhancing technological innovation and improving green activities. Therefore, green supply chain management is a growing complex challenge for enterprises nowadays [33]. In reality, many enterprises can gain benefits from green actions [34]. In addition, these sustainable enterprises can provide solutions for fulfilling elementary needs to improve the lives of people, now and in the future, with the least possible environmental impacts and the highest possible economic and social yield [35-37]. With the enhancement of consumers' awareness of environmental protection, the research on the coordinated management of green supply chains has attracted increasing attention from academia. For example, Zhao et al. (2012) [38] used game theory to analyze the strategies selected by manufacturers to reduce life cycle environmental risk of materials and carbon emissions. Zhang and Liu (2013) [39] studied coordination mechanisms in a three-level green supply chain under a non-cooperative game. Zhang et al. (2014) [40] studied pricing and coordination strategy of green supply chain under hybrid production mode. Chatterjee et al. (2016) [41] used the grey DEMATEL-ARAS model to identify key influencing criteria in forecasting and selecting suppliers that help companies solve decision making problems in an imprecise environment. Based on this foundation, he evaluated the performance of suppliers based on using the R'AMATEL-MAIRCA method for green supply chain implementation in electronics industry [42]. Zhu and He (2017) [43] studied how supply chains' decisions with respect to the "greenness" of products are affected by factors such as supply chain structures, the green product types, and the types of competition (price competition and greenness competition). Liu and Yi (2017) [44] studied pricing policies of the green supply chain considering targeted advertising and product green degree in the Big Data environment. Wei et al. (2018) [45] presented the pricing decisions of complementary products in a supply chain including two manufacturers and one retailer under centralized and decentralized decision cases, respectively. Tang and Wei (2018) [46] modeled green supplier selection in green supply chain management with 
pythagorean2-tuple linguistic information. Hong and Guo (2018) [47] studied green product supply chain contracts considering environmental responsibilities. Chen et al. (2020) [48] introduced the concept of equity as the incentive mechanism to coordinate the green supply chain. Sarkar and Bhadouriya (2020) [49] studied manufacturer competition and collusion in a two-echelon green supply chain with production trade-off between non-green and green quality. Shan et al. (2020) [50] constructed three pricing models to simultaneously analyze the changes in the optimal profits of supply chain members and the optimal degree of green manufacturing of complementary products. Li et al. (2020) [51] introduced a strategy-structure-performance framework to explore the mechanism through which proactive environmental strategies improve environmental performance by using green supply chain integration. Su et al. (2020) [52] explored how to arrange the generation and pricing of supply chain members in the case of consumer green preference with different government subsidies.

\section{Problem Description}

The improvement of the greenness of retail store brand products can increase consumer preference and the market demand for the products. Therefore, it is necessary for the retailer and the upstream manufacturer to manage the greenness of the product in coordination, so that both sides can achieve the goal of a win-win situation. However, the greenness of a retail store brand requires a lot of environmental investment, including the fixed production facilities for energy conservation and emission reduction, invested at one time in the early stage, which is a fixed cost of green product production. It also includes variable investment in the product production process, such as green packaging in the production process, which is the variable cost of green product production. In addition, it includes the cost of green product sales, such as green publicity, green advertising, and so on. In the entrusted production mode of a retail store brand, the retailer's one-off environmental investment in the early stage of energy conservation and emission reduction can improve the enthusiasm of upstream manufacturers' environmental investment. However, on one hand, the high proportion of the retailer's undertaking with respect to environmental investment will reduce the retailer's profit, and on the other hand, the retailer's one-off environmental investment in the early stage will face the problem of investment binding due to the sunk cost, which will reduce the retailer's bargaining power, while the upstream manufacturer may not strive to increase their own environmental investment. According to classical negotiation theory, in the process of enterprise cooperation, the party with stronger bargaining power will get more benefits, while the party with weaker bargaining power will get less benefits. In general, the shift of negotiation strength between the retailer and the manufacturer affects the environmental investment and benefits of all parties. Based on the above analysis, this paper takes the negotiation strengths of the retailer and the manufacturer as an important parameter, investigates the impact of retailers' different types of early-stage one-time environmental input allocation mode and negotiation strength changes on the greenness and the profits of all parties on the basis of building a Nash negotiation model.

According to the different degrees of retailer participation in the early stage of green products, there are generally three production modes in the retailer leading green supply chain, including OEM mode, full participation mode and partial participation mode. According to these three production modes, there are three situations in the allocation of environmental investment between the retailer and the manufacturer: (i) in the mode of the retailer-direct OEM, the retailer directly OEM products without undertaking the one-off environmental investment in the early stage, and the one-off environmental investment in the early stage is invested by the manufacturer in the production process (we call it mode A). The decision-making order of model A is as follows: First, the retailer determines the greenness of the product. Second, the retailer lets the manufacturer participate in the production through a bidding mechanism, the retailer and the manufacturer negotiate to decide the product's wholesale price $w$ and the product's purchase deposit $G$. Third, the manufacturer produces the product and undertakes the variable production cost of the green product. Fourth, the retailer purchases the product from the manufacturer and the retailer undertakes the cost of the green product sales, then 
labels it and sells it at market price. (ii) In full participation mode which is totally designed and participated in by the retailer, the retailer may fully undertake the one-off environmental investment in the early stage (we call it mode B) in order to establish a brand image and to improve the product's greenness. In mode $B$, the retailer designs green products independently and participates in the green management of products. The retailer obtains the green management rights of products through a complete one-off environmental investment in the early stage. The decision-making sequence of mode B is as follows: First, the retailer determines the greenness of the product, and makes a one-off environmental investment in the early stage. Second, the retailer lets the manufacturer participate in the production through bidding, and the retailer and the manufacturer negotiate to determine the wholesale price of the product $w$ and the product's purchase deposit $G$. Third, the manufacturer produces the product and undertakes the variable production cost of the green product. Fourth, the retailer purchases the product from the manufacturer and undertakes the cost of the green product sales, labels it and sells it at market price $p$. (iii) In the partial participation mode, which is partially designed and participated in by the retailer, the retailer moderately participates in the design of green products, the retailer and the manufacturer jointly undertake the one-off environmental investment in the early stage, and the subsequent decision-making sequence is the same as mode A and mode B. Next, we build models based on these three production modes.

\section{Modeling}

We make the following assumptions to facilitate the analysis of the problem:

(i) We assume that the retail store brand green supply chain consists of a retailer $R$ and an upstream manufacturer $M$. The retailer's relative negotiation strength is $\mu$, and the upstream manufacturer's relative negotiation strength is $1-\mu(\mu \in[0,1])$, assuming that there is no cost in the negotiation between the retailer and the manufacturer.

(ii) The green cost of retail store brand product includes three parts: the first part is the initial one-off investment in the production process of the green product, such as green design, large-scale sewage equipment and other green production facilities. The second part is the marginal cost of green product production, such as green packaging of products. The third part is the sales cost of green products, such as green advertising. We assume that the fixed cost of one-off environmental investment in the early stage of a green product is $c_{1}(\theta)=\frac{1}{2} c_{1} \theta^{2}$ [53-55], the marginal production cost is $c_{2}(\theta)=c_{2} \theta$, and the marginal sales cost of the product is $c_{3}(\theta)=c_{3} \theta$, where $\theta$ is the greenness of the product, and $c_{1}, c_{2}, c_{3}$ are constants greater than or equal to zero and less than 1 .

(iii) We assume that the market demand of the retail store brand green product $q$ is a decreasing function of the sales price $p$ and an increasing function of the green degree $\theta$, whose demand function is $q(p, \theta)=1-\frac{p}{\theta}[56,57]$, where $c_{2}+c_{3}<1$ with differentiable conditions.

(iv) We assume that both the retailer and the manufacturer are risk neutral, the retailer and the manufacturer are in line with the reasonable economic person hypothesis, and pursue the maximization of their own interests.

(v) We assume that the manufacturer undertakes the marginal cost of green product production and the retailer undertakes the marginal cost of green product sales. According to the three different production modes, the initial one-off environmental investment of green product in the early can be undertaken by the manufacturer alone (mode A), by the retailer alone (mode B), or by both (mode C). We assume that the proportion of the initial one-off environmental investment undertaken by the retailer is $\gamma(\gamma \in[0,1])$, the proportion of the initial one-off environmental investment undertaken by the manufacturer is $1-\gamma(1-\gamma \in[0,1]), \gamma=1$ means that the retailer undertakes all the first-time environmental investment, $\gamma=0$ means that the manufacturer undertakes all the one-off environmental investment in the early stage, and $0<\gamma<1$ means that the seller and the manufacturer jointly undertake the initial one-off environmental investment. 
According to the two-part charging transaction law and the initial one-off environmental investment mode of green products in the early stage, we can get the total profit of retailer, manufacturer and green supply chain as follows:

$$
\begin{gathered}
\prod_{M}=\left(w-c_{2}(\theta)\right) q(p, \theta)+G-(1-\gamma) c_{1}(\theta) \\
\prod_{R}=\left(p(w, \theta)-w-c_{3}(\theta)\right) q(p, \theta)-G-\gamma c_{1}(\theta) \\
\prod_{S C}=\left(p(w, \theta)-c_{2}(\theta)-c_{3}(\theta)\right) q(p, \theta)-c_{1}(\theta)
\end{gathered}
$$

By the reverse method, we can see that the optimal sales price of production three different production modes can be determined by $\max _{p}\left\{\prod_{R}(p, w, G, \theta)\right\}$, and the optimal sales price and product demand of green product are as follows:

$$
\left\{\begin{array}{l}
p(w, \theta)=\frac{\theta+w+c_{3}(\theta)}{2} \\
q(p, \theta)=\frac{\theta-w-c_{3}(\theta)}{2 \theta}
\end{array}\right.
$$

Under the three different production modes of $\mathrm{A}, \mathrm{B}$ and $\mathrm{C}$, the negotiation process between the retailer and the manufacturer on the purchase right deposit $G$, wholesale price $w$ and product greenness $\theta$ of entrusted production is a process of maximizing their own profits. Mode A and mode $B$ are negotiation problems with respect to $(G, w)$, mode $C$ is the negotiation problem with respect to $(G, w, \theta)$. The extension of negotiation model in this paper has also been used in Battigalli [58]. Three situations can be transformed into the following problems:

$$
\begin{aligned}
& \max _{\psi}\left\{\mu \ln \left(\prod_{R}-\prod_{\sim}\right)+(1-\mu) \ln \left(\prod_{M}-\prod_{\sim}\right)\right\} \\
& \max _{\psi}\left\{\mu \ln \left(\prod_{R}-\prod_{\sim}\right)+(1-\mu) \ln \left(\prod_{M}-\prod_{\tilde{\sim}}\right)\right\} \\
& \operatorname{s.t}\left(p(w, \theta)-w-c_{3}(\theta)\right) q(p, \theta)-G-\gamma c_{1}(\theta) \geq 0 \\
& \left(w-c_{2}(\theta)\right) q(p, \theta)+G-(1-\gamma) c_{1}(\theta) \geq 0 \\
& p(w, \theta) \geq w \geq c_{2}(\theta) \geq 0, c_{1}(\theta) \geq 0, c_{3}(\theta) \geq 0 \\
& 1 \geq \mu \geq 0, q(p, \theta) \geq 0,1 \geq \gamma \geq 0
\end{aligned}
$$

Among the above formulas, $\psi=(G, w)$ under mode $\mathrm{A}$ and $\mathrm{B}, \psi=(G, w, \theta)$ under mode $\mathrm{C}$. To compare the coordination effect of greenness, this paper first studies the optimal equilibrium result under the centralized control strategy (marked as IC). We can easily obtain the following results by reverse derivation method from the formula $\max _{p}\left\{\prod_{S C}(p, \theta)\right\}$ : the optimal selling price of green products is $p=\frac{\theta\left(1+c_{2}+c_{3}\right)}{2}$, the optimal greenness under the IC strategy is $\theta^{I C}=\frac{\left(1-c_{2}-c_{3}\right)^{2}}{4 c_{1}}$, and the optimal total profit of green supply chain is $\prod_{S C}^{I C}=\frac{\left(1-c_{2}-c_{3}\right)^{4}}{32 c_{1}}$.

\section{Cooperative Coordination of Green Supply Chain under Different Production Modes}

\subsection{Cooperative Coordination of Green Supply Chain under Mode A}

First of all, we analyze the situation in which the retailer does not undertake the one-off environmental investment in the early stage of its store brand products; it coordinates the green supply chain and obtain the optimal greenness of product and the optimal profit balance solution of all parties under the strategy through the negotiation of the wholesale price and the advance purchase deposit. 
Under mode A, the manufacturer's retained profit is $\prod_{\sim}^{A}=-c_{1}(\theta)$, and the retailer's retained profit is $\prod_{R}^{A}=0$. From Equation (5), the negotiation between the retailer and the manufacturer about the wholesale price of green products and the deposit of purchase right can be transformed into the following formula:

$$
\begin{aligned}
& \max _{G, w}\left\{\mu \operatorname { l n } \left[\left(p^{A}(w, \theta)-w-c_{3}(\theta)\right) q^{A}(p, \theta)\right.\right. \\
& \left.-G]+(1-\mu) \ln \left[\left(w-c_{2}(\theta)\right) q^{A}(p, \theta)+G\right]\right\}
\end{aligned}
$$

The following result can be got from Equation (6):

$$
\begin{aligned}
& G(w, \theta)=(1-\mu) p^{A}(w, \theta) q^{A}(p, \theta)-(w \\
& \left.-\mu c_{2}(\theta)\right) q^{A}(p, \theta)-(1-\mu) c_{3}(\theta) q^{A}(p, \theta)
\end{aligned}
$$

The following result can be obtained by sorting Equation (7):

$$
\begin{aligned}
& (1-\mu) \ln (1-\mu)+\mu \ln \mu+\max _{w} \ln [ \\
& \left.p^{A}(w, \theta)-c_{2}(\theta)-c_{3}(\theta)\right] q^{A}(p, \theta)
\end{aligned}
$$

In Equation (8), let $\partial\left(p^{A}(w, \theta)-c_{2}(\theta)-c_{3}(\theta)\right) q^{A}(p, \theta) / \partial \theta=0$ and the optimal wholesale price of green product can be solved: $w^{A}=c_{2} \theta$.

Under mode A, the optimal greenness of the product is determined by the profit maximization condition of the manufacturer, so the optimal greenness can be solved:

$$
\theta^{A}=\frac{(1-\mu)\left(1-c_{2}-c_{3}\right)^{2}}{4 c_{1}}
$$

Let $S=\left(1-c_{2}-c_{3}\right)^{2} / 16 c_{1}$, by substituting $\theta^{A}$ into the corresponding formula, we can obtain the optimal sales price $p^{A}$ of green product, the optimal purchase deposit $G^{A}$ and the optimal wholesale price $W^{A}$ of green product:

$$
\left\{\begin{array}{l}
p^{A}=2(1-\mu)\left(1+c_{2}+c_{3}\right) S \\
G^{A}=(1-\mu)^{2}\left(1-c_{2}-c_{3}\right)^{2} S \\
w^{A}=4(1-\mu) c_{2} S
\end{array}\right.
$$

Let $J=\left(1-c_{2}-c_{3}\right)^{4} / 32 c_{1}$, by substituting $\theta^{A}$ into the corresponding profit formula of retailer and manufacturer, we can get the optimal profit of retailer $\prod_{R}^{A}$, the optimal profit of manufacturer $\prod_{M^{\prime}}^{A}$ and the optimal profit of green supply chain $\prod_{S C}^{A}$ :

$$
\left\{\begin{array}{l}
\prod_{R}^{A}=2 \mu(1-\mu) J \\
\prod_{M}^{A}=(1-\mu)^{2} J \\
\prod_{S C}^{A}=\left(1-\mu^{2}\right) J
\end{array}\right.
$$

Proposition 1. Under mode A, (i) The optimal greenness of the product, the optimal total profit of the supply chain and the optimal profit of the manufacturer are the decreasing functions of the retailer's negotiation strength $\mu(\mu \in[0,1]$ ). (ii) When the retailer's negotiation strength is in the interval $\mu \in[0,0.5]$, the retailer's optimal profit is the increasing function of its negotiation strength. When the retailer's negotiation strength is in the interval $\mu \in[0.5,1]$, the retailer's optimal profit is the decreasing function of its negotiation strength in the interval. (iii) When the retailer's negotiation strength is in the interval $\mu \in[0.5,1]$, the increase of retailer's negotiation strength will lead to the decrease of greenness, retailer's optimal profit, manufacturer's optimal profit and supply chain's total profit, thus resulting in the double marginal profit decreasing problem of retailer and manufacturer in the process of cooperation. 
Proof. First of all, because the optimal greenness of product under mode A is $\theta^{A}=4(1-\mu) S$, the first-order function of negotiation strength to the retailer is $\partial \theta^{A} / \partial \mu=-4 S \leq 0$, so $\theta^{A}$ is the subtractive function of $\mu$. Secondly, because the first-order function of manufacturer's optimal profit to retailer's negotiation strength is satisfied $\partial \prod_{M}^{A} / \partial \mu=-2(1-\mu) J \leq 0$ and the first-order function of green supply chain's optimal total profit to retailer's negotiation strength is satisfied $\partial \prod_{S C}^{A} / \partial \mu=-2 \mu J \leq 0$, both $\prod_{M}^{A}$ and $\prod_{S C}^{A}$ are the decreasing functions of retailer's negotiation strength. Finally, because the first-order function of retailer's optimal profit to its negotiation strength is $\partial \prod_{R}^{A} / \partial \mu=(1-2 \mu) J$, when the retailer's negotiation strength is in the interval $\mu \in[0,0.5]$, the retailer's optimal profit is the increasing function of its negotiation strength. When the retailer's negotiation strength is in the interval $\mu \in[0.5,1]$, the greenness of the retail store brand product, the retailer's optimal profit and the manufacturer's optimal profit are the subtractive functions of the retailer's negotiation strength.

It can be seen from Proposition 1 that under the entrusted production mode A, the enhancement of the retailer's negotiation strength will increase the risk of manufacturer's one-off environmental investment in the early stage, and the one-off environmental investment in the early stage is uneconomical for the manufacturer. Therefore, the increase of the retailers' negotiation strength will reduce the enthusiasm of manufacturers' one-off environmental investment in the early stage, and then reduce the optimal greenness of product. In other words, under production mode A, the enhancement of retailers' negotiation strength will always damage the greenness of the store brand product, the total profit of the supply chain, and the profit of the manufacturer.

Secondly, it can be seen from Proposition 1 that under mode A, when the negotiation strength of the retailer is in a weak position $(\mu \in[0,0.5])$, although the increase in the retailer's negotiation strength can increase its profit, it will reduce the manufacturer's profit and enthusiasm for the initial one-off environmental investment. However, when the retailer's bargaining power is further enhanced and exceeds $\mu=0.5$, both the retailer's and the manufacturer's profit will decrease with the increase of the retailer's bargaining power, which leads to the problem of diminishing double marginal profits for all partners.

In general, mode A directly produces green products with labels, and the retailer does not undertake the one-off environmental investment in the early stage of store brand green product. It seems that the retailer does not undertake the investment risk and it is beneficial to the retailer in this case. However, with the enhancement of negotiation strength of the retailer, especially after the negotiation strength of retailers exceeds the threshold of 0.5 , mode $\mathrm{A}$ is not beneficial for the retailer to improve the greenness of store brand products and the total profit of supply chain. It may even reduce the retailer's profit in this case.

\subsection{Cooperative Coordination of Green Supply Chain under Mode B}

Under production mode $B$, the retailer fully undertakes the initial one-off environmental investment of store brand green product, the wholesale price and the deposit of purchase right are determined by negotiation. Under mode B, the manufacturer's retained profit is $\prod_{\sim}^{B}=0$, the retailer's retained profit is $\prod_{\sim}^{B}=-c_{2}(\theta)$, and the retailer's optimal greenness decision can be obtained through $\partial \prod_{R}^{B} / \partial \theta=0$. According to the same derivation process in above section, we can calculate the optimal sales price $p^{B}$ of green products under production mode $B$, the optimal purchase right deposit $G^{B}$, the optimal wholesale price $w^{B}$, the optimal greenness $\theta^{B}$, the retailer's optimal profit $\prod_{R}^{B}$, the manufacturer's optimal profit $\prod_{M}^{B}$, and the supply chain's optimal total profit $\prod_{S C}^{B}$ as follows: 


$$
\left\{\begin{array}{l}
p^{B}=2 \mu\left(1+c_{2}+c_{3}\right) S \\
G^{B}=(1-\mu)\left(1-c_{2}-c_{3}\right)^{2} S \\
w^{B}=4 \mu c_{2} S \\
\theta^{B}=\frac{\mu\left(1-c_{2}-c_{3}\right)^{2}}{4 c_{1}} \\
\prod_{R}^{B}=\mu^{2} J \\
\prod_{M}^{B}=2 \mu(1-\mu) J \\
\prod_{S C}^{B}=\mu(2-\mu) J
\end{array}\right.
$$

Proposition 2. Under mode B, (i) The optimal greenness of the product, the optimal profit of the retailer and the optimal total profit of the green supply chain are the increasing functions of the retailer's negotiation strength $\mu(\mu \in[0,1])$. (ii) When the retailer negotiation strength is in the interval $\mu \in[0,0.5]$, the manufacturer's optimal profit is the increasing function of the retailer's negotiation strength; when the retailer negotiation strength is in the interval $\mu \in[0.5,1]$, the manufacturer's optimal profit is the decreasing function of the retailer's negotiation strength. (iii) Although mode B eliminates the double diminishing marginal profit problem that the greenness and each party's profit decrease with the increase of retailer's negotiation strength, it is not the optimal green product environmental input coordination mode of store brand.

Proof. First of all, because the optimal total profit, retailer's optimal profit and product's optimal greenness of the green supply chain's first derivative of the retailer's negotiation strength satisfies $\partial \prod_{S C}^{B} / \partial \mu=2(1-\mu) \geq 0, \partial \prod_{R}^{B} / \partial \mu=2 \mu J \geq 0, \partial \theta^{B} / \partial \mu=\frac{\mu\left(1-c_{2}-c_{3}\right)}{2 c_{2}}>0$, so $\prod_{S C^{\prime}}^{B} \prod_{R^{\prime}}^{B}, \theta^{B}$ are increasing functions of the retailer's negotiation strength $\mu$. Secondly, because the first derivative of the manufacturer's optimal profit to retailer's negotiation strength is $\partial \prod_{M}^{B} / \partial \mu=2(1-2 \mu) J$, when the retailer's negotiation strength is in the interval $\mu \in[0,0.5]$, the derivative equation satisfies $\partial \prod_{M}^{B} / \partial \mu \geq 0$, the manufacturer's optimal profit is the increasing function of retailer's negotiation strength. When the retailer's negotiation strength is in the interval $\mu \in[0.5,1]$, the derivative equation satisfies $\partial \prod_{M}^{B} / \partial \mu \leq 0$, and the manufacturer's optimal profit is the decreasing function of retailer's negotiation strength. Finally, because the optimal greenness formula of products under the vertical centralized control strategy is $\theta^{I C}=\frac{\left(1-c_{2}-c_{3}\right)^{2}}{4 c_{1}}$ and $\frac{\left(1-c_{2}-c_{3}\right)^{2}}{4 c_{1}} \geq \frac{\mu\left(1-c_{2}-c_{3}\right)^{2}}{4 c_{1}}$, the equation satisfies $\theta^{B} \leq \theta^{I C}$, and the optimal greenness of products under the mode $B$ is less than that under the vertical centralized control.

It can be seen from Proposition 2 that if the retailer completely undertakes the one-off environmental investment of store brand green product in the early stage, it can eliminate the dual diminishing marginal profit problem that the retailer's profit decreases with the increase of its negotiation strength. However, although the increase of the retailers' negotiation strength is always conducive to the improvement of store brand product's environment investment level and the increase of retailer's profit with the increase of retailers' negotiation strength. Especially when the retailer is in a strong position, that is $\mu \in[0.5,1]$, the manufacturer's profit will decrease and it will weaken the enthusiasm of the manufacturer's cooperation. In addition, the optimal greenness of the product is still less than that of the centralized control strategy. That is to say, the retailer's one-off environmental investment in the early stage of undertaking its store brand green product is not the best coordination mode of its store brand green product, and there may be a better coordination mode.

\subsection{Cooperative Coordination of Green Supply Chain under Mode C}

Under production mode $C$, the manufacturer's retained profit is $\prod_{M}^{C}=-(1-\gamma) c_{2}(\theta)$, and the retailer's retained profit is $\prod_{\sim}^{C}=-\gamma c_{2}(\theta)$. According to the similar derivation process in Section 5.2 above, we can calculate that the proportion of fixed investment undertaken by the retailer in the early 
stage $\gamma$, the optimal sales price of green product $p^{C}$, the optimal purchase right deposit $G^{C}$, the optimal wholesale price $w^{C}$, the optimal greenness of product $\theta^{C}$, the optimal profit of retailer $\prod_{R^{\prime}}^{C}$ the optimal profit of manufacturer $\prod_{M}^{C}$, the optimal total profit of green supply chain $\prod_{S C}^{C}$ are:

$$
\left\{\begin{array}{l}
\gamma=\mu \\
p^{C}=2 \mu\left(1+c_{2}+c_{3}\right) S \\
G^{C}=(1-\mu)\left(1-c_{2}-c_{3}\right)^{2} S \\
w^{C}=4(1-\mu) c_{2} S \\
\theta^{C}=\frac{\left(1-c_{2}-c_{3}\right)^{2}}{4 c_{1}} \\
\prod_{R}^{C}=\mu J \\
\prod_{M}^{C}=(1-\mu) J \\
\prod_{S C}^{C}=J
\end{array}\right.
$$

Proposition 3. (i) Under mode $C$, the optimal greenness of product and the optimal total profit of supply chain are not related to the negotiation strength of the retailer, but related to the marginal cost coefficient of production, the one-off environmental input cost coefficient and the cost coefficient of sales. (ii) Under mode $C$, the retailer's optimal profit is the increasing function of its negotiation strength, and the manufacturer's optimal profit is the decreasing function of the retailer's negotiation strength. (iii) Model C realizes the optimal environmental input coordination of the greenness of store brand product, which is independent of the negotiation strength of the retailer and equivalent to the greenness under the centralized control strategy.

Proof. First of all, because the optimal greenness of products and the optimal total profit of supply chain are $\theta^{C}=\frac{\left(1-c_{2}-c_{3}\right)^{2}}{4 c_{1}}, \prod_{S C}^{C}=J=\frac{\left(1-c_{2}-c_{3}\right)^{4}}{32 c_{1}}$, respectively, under mode $C$, it is not difficult to see that the optimal greenness of the product and the optimal total profit of the supply chain are independent of the negotiation strength of the retailer $\mu$.

Secondly, because the first derivative of the retailer's optimal profit and the manufacturer's optimal profit to the retailer's negotiation strength satisfies $\partial \prod_{R}^{C} / \partial \mu=J>0, \partial \prod_{M}^{C} / \partial \mu=-J<0$, the retailer's optimal profit is the increasing function of the retailer's negotiation strength under mode $\mathrm{C}$, and the manufacturer's optimal profit is the decreasing function of retailer's negotiation strength.

Finally, comparing the greenness of the product under the mode $C$ and the vertical centralized control strategy, we can find that mode $C$ realizes the greenness which is independent of the retailer's negotiation strength and equivalent to the centralized control strategy, and realizes the optimal environmental input coordination of the store brand product.

Through Proposition 3, it can be found that the retailer should appropriately undertake the initial one-off environmental investment for the store brand green product under mode $\mathrm{C}$. Although the manufacturer's profit will decrease with the increase in the retailer's negotiation strength, it does not affect the enthusiasm of the manufacturer for environmental investment, because the joint undertaking of the initial one-off environmental investment reduces the investment risk for the manufacturer. Even in the case of strong negotiation ability of the retailer, that is, in the interval $\mu \in[0.5,1]$, the manufacturer still has the enthusiasm of environmental investment, because the one-off environmental investment in the early stage of the retailers reduces the hold-up possibility of the manufacturers' investment.

Proposition 3 also shows that the retailer can achieve the effect that the retailer's optimal total profit increases with the increase of its negotiation strength. In Proposition 3, the greenness of the store brand product and the optimal total profit of the supply chain are related to the marginal cost coefficient of the green product, the sales cost coefficient, and the coefficient of the initial one-off environmental investment, and are independent of the retailer's negotiation strength. 


\section{Analysis and Comparison of Different Entrusted Production Modes}

Proposition 4. The priority for the retailer to choose different production modes is:

(i) When $0 \leq \mu \leq \frac{1}{2}, \prod_{R}^{B} \leq \prod_{R}^{C} \leq \prod_{R}^{A}$.

(ii) When $\frac{1}{2} \leq \mu \leq \frac{2}{3}, \prod_{R}^{B} \leq \prod_{R}^{C} \leq \prod_{R}^{A}$.

(iii) When $\frac{2}{3} \leq \mu \leq 1, \prod_{R}^{A} \leq \prod_{R}^{B} \leq \prod_{R}^{C}$.

Proof. It can be seen from the retailer's profit formula in Equations (11) and (13), when $\mu^{A}=\mu^{C}=0$, $\prod_{R}^{A}=\prod_{R}^{C}=0$. When $\mu^{A}=\mu^{C}=\frac{1}{2}, \prod_{R}^{A}=\prod_{R}^{C}=\frac{1}{2} J$. Because when the retailer's negation strength is in the interval $\mu \in\left[0, \frac{1}{2}\right], \prod_{R}^{A}$ is increasing function of $\mu, \prod_{R}^{C}$ is increasing function of $\mu$. When the retailer's negation strength is in the interval $\mu \in\left[\frac{1}{2}, 1\right], \prod_{R}^{A}$ is decreasing function of $\mu, \prod_{R}^{C}$ is increasing function of $\mu$. So we can get the result that when $\mu \in\left[0, \frac{1}{2}\right], \prod_{R}^{C} \leq \prod_{R}^{A}$, when $\mu \in\left[\frac{1}{2}, 1\right]$, $\prod_{R}^{A} \leq \prod_{R}^{C}$. According to the same reasoning process as above, when $\mu \in\left[0, \frac{2}{3}\right], \prod_{R}^{A} \geq \prod_{R}^{B}$, when $\mu \in\left[\frac{2}{3}, 1\right], \prod_{R}^{A} \leq \prod_{R}^{B}$, when $\mu \in[0,1], \prod_{R}^{C} \geq \prod_{R}^{B}$. From the above analysis we can get the result that: (i) When $0 \leq \mu \leq \frac{1}{2}, \prod_{R}^{B} \leq \prod_{R}^{C} \leq \prod_{R}^{A}$. (ii) When $\frac{1}{2} \leq \mu \leq \frac{2}{3}$, $\prod_{R}^{B} \leq \prod_{R}^{C} \leq \prod_{R}^{A}$. (iii) When $\frac{2}{3} \leq \mu \leq 1$, $\prod_{R}^{A} \leq \prod_{R}^{B} \leq \prod_{R}^{C}$.

Proposition 4 shows that when the negotiation strength of the retailer is less than 0.5 and the negotiation strength of the retailer is in a weak position, the retailer tends to choose mode $\mathrm{A}$, that is, to let the manufacturer undertake all the initial environmental investment. When the negotiation strength of the retailer is greater than 0.5 , that is, when the retailer is in a strong position, the retailer tends to choose mode $C$, that is, to let the retailer and the manufacturer jointly undertake the initial one-off environmental investment of green product. For the retailer, when $0 \leq \mu \leq \frac{1}{2}$, mode $B$ is the worst choice, and mode $C$ is the suboptimal choice. When $\frac{1}{2} \leq \mu \leq \frac{2}{3}$, mode $B$ is the worst choice, and mode $\mathrm{A}$ is the suboptimal choice. When $\frac{2}{3} \leq \mu \leq 1$, mode $\mathrm{A}$ is the worst choice, and mode $\mathrm{B}$ is the suboptimal choice. Therefore, no matter how strong the retailer's bargaining power is, mode $C$ is not the worst choice for the retailer. In conclusion, mode $C$ is either the best choice or the suboptimal choice for the retailer.

Proposition 5. The priority for the manufacturer to choose different production modes is:

(i) When $0 \leq \mu \leq \frac{1}{3}, \prod_{M}^{B} \leq \prod_{M}^{A} \leq \prod_{M}^{C}$.

(ii) When $\frac{1}{3} \leq \mu \leq \frac{1}{2}, \prod_{M}^{A} \leq \prod_{M}^{B} \leq \prod_{M}^{C}$.

(iii) When $\frac{1}{2} \leq \mu \leq 1, \prod_{M}^{A} \leq \prod_{M}^{C} \leq \prod_{M}^{B}$.

Proof. Because when $\mu^{A}=\mu^{C}=0, \prod_{M}^{A}=\prod_{M}^{C}=J$. When $\mu^{A}=\mu^{C}=\frac{1}{3}, \prod_{M}^{A}=\frac{4}{9} J, \prod_{M}^{C}=\frac{2}{3} J$, we can get the result $\prod_{M}^{C}>\prod_{M}^{A}$. Because when $\mu$ is in the interval $\mu \in\left[0, \frac{1}{3}\right], \prod_{M}^{A}$ and $\prod_{M}^{C}$ are all decreasing functions of $\mu$, with the result that when $\mu$ is in the interval $\mu \in\left[0, \frac{1}{3}\right], \prod_{M}^{A} \leq \prod_{M}^{C}$. Because when $\mu^{B}=0, \prod_{M}^{B}=0$. When $\mu^{A}=\mu^{B}=\frac{1}{3}, \prod_{M}^{A}=\prod_{M}^{B}=\frac{4}{9} J$. When $\mu$ is in the interval $\mu \in\left[0, \frac{1}{3}\right], \prod_{M}^{A}$ is decreasing function of $\mu, \prod_{M}^{B}$ is increasing function of $\mu$, in the result we can get $\prod_{M}^{B} \leq \prod_{M}^{A}$ in the interval $\mu \in\left[0, \frac{1}{3}\right]$. Summarizing the previous reasoning process we can get the result $\prod_{M}^{B} \leq \prod_{M}^{A} \leq \prod_{M}^{C}$ when $\mu$ is in the interval $\mu \in\left[0, \frac{1}{3}\right]$. According to the same reasoning process ahead, it is easy to prove that $\prod_{M}^{A} \leq \prod_{M}^{B} \leq \prod_{M}^{C}$ when $\mu \in\left[\frac{1}{3}, \frac{1}{2}\right], \prod_{M}^{A} \leq \prod_{M}^{C} \leq \prod_{M}^{B}$ when $\mu \in\left[\frac{1}{2}, 1\right]$.

Proposition 5 shows that when the negotiation strength of the retailer is less than 0.5 , that is, the retailer is in a weak position, and the manufacturer is in a strong position, the manufacturer tends to choose mode $C$, in which the retailer and the manufacturer share the initial one-off environmental investment of green product. When the negotiation strength of the retailer is greater than 0.5 , that is, the retailer is in a strong position, and the manufacturer is in a weak position, the manufacturer tends to choose mode $B$, which allows the retailer to undertake all the green one-off environmental investment 
in the early stage, and lets the retailer to undertake the risk of one-off environmental investment in the early stage alone.

Proposition 5 also shows that for the manufacturer, mode B is the worst choice and mode $A$ is the suboptimal choice when $0 \leq \mu \leq \frac{1}{3}$. When $\frac{1}{3} \leq \mu \leq \frac{1}{2}$, mode $\mathrm{A}$ is the worst choice and mode $\mathrm{B}$ is the suboptimal choice. When $\frac{1}{2} \leq \mu \leq 1$, mode $\mathrm{A}$ is the worst choice and mode $\mathrm{C}$ is the suboptimal choice. Therefore, no matter how strong the retailer's bargaining power, mode $C$ is not the worst choice for the manufacturer. In conclusion, mode $\mathrm{C}$ is either the best choice or the suboptimal choice for the manufacturer.

Proposition 6. (i) From the perspective of greenness coordination effect, we can get $\theta^{C} \geq \theta^{A}, \theta^{C} \geq \theta^{B}$. (ii) From the perspective of coordination effect of green supply chain's total profit, we can get $\prod_{S C}^{C} \geq \prod_{S C^{\prime}}^{A}$, $\prod_{S C}^{C} \geq \prod_{S C}^{B}$. (iii) $\theta^{C}=\theta^{I C}, \prod_{S C}^{C}=\prod_{S C}^{I C}$.

Proof. (i) From Equations (9), (12) and (13), we can get $\theta^{A}=\frac{(1-\mu)\left(1-c_{2}-c_{3}\right)^{2}}{4 c_{1}}, \theta^{B}=\frac{\mu\left(1-c_{2}-c_{3}\right)^{2}}{4 c_{1}}$, $\theta^{C}=\frac{\left(1-c_{2}-c_{3}\right)^{2}}{4 c_{1}}$, we can get the result $\theta^{C} \geq \theta^{A}$ and $\theta^{C} \geq \theta^{B}$ because $\mu \in[0,1]$. (ii) From Equations (11)-(13), we can get $\prod_{S C}^{C}=J, \prod_{S C}^{B}=\mu(2-\mu) J, \prod_{S C}^{A}=\left(1-\mu^{2}\right) J$, and it is easy to compute $\prod_{S C}^{C}-\prod_{S C}^{A}=\mu^{2} J \geq 0, \prod_{S C}^{C}-\prod_{S C}^{B}=(1-\mu)^{2} J \geq 0$, so we can get the result $\prod_{S C}^{C} \geq \prod_{S C}^{A}, \prod_{S C}^{C} \geq \prod_{S C}^{B}$. (iii) From Equation (13) we can get the result $\theta^{C}=\theta^{I C}, \prod_{S C}^{C}=\prod_{S C}^{I C}$.

Proposition 6 shows that among the three modes, the greenness of mode $C$ and the coordination effect of total profit of supply chain are always the best, and they are equivalent to the best state of vertical centralized control IC mode. Under mode C, the greenness of products and the total profit of green supply chain are not related to the negotiation strength of the retailer. From the perspective of product greenness, when the retailer is in a strong position, mode B is better than mode $A$. When the retailer is in a weak position, mode $\mathrm{A}$ is better than mode $\mathrm{B}$.

Proposition 7. According to the equilibrium principle of Nash negotiation, when the two sides choose mode $C$, the retailer should give the manufacturer a subsidy of $\Delta=(1-\mu)^{3} J$, the retailer's optimal profit is $\overline{\bar{\Pi}}_{R}^{C}=\left[\mu-(1-\mu)^{3}\right] J$, and the manufacturer's optimal profit is $\overline{\bar{\Pi}}_{M}^{C}=(1-\mu)\left(2-2 \mu+\mu^{2}\right) J$.

Proof. It can be seen from Propositions 4 and 5 that when $\mu \in\left[0, \frac{1}{2}\right]$, the retailer tends to choose mode $\mathrm{A}$, while the manufacturer tends to choose mode $\mathrm{C}$. When $\mu \in\left[\frac{1}{2}, 1\right]$, the manufacturer tends to choose mode $B$, while the retailer tends to choose mode $C$, so the conflict between the two sides' mode selection needs to be resolved through negotiation. If the two parties choose mode $\mathrm{C}$, one party must give the other a certain amount of subsidy. When $\mu \in\left[\frac{1}{2}, 1\right], \Delta_{R}=\prod_{R}^{C}-\prod_{R}^{B}=\left(\mu-\mu^{2}\right) J$, $\Delta_{M}=\prod_{M}^{B}-\Pi_{M}^{C}=\left(3 \mu-2 \mu^{2}-1\right) J$, so the profit gap between the retailer and the manufacturer is $\Delta_{R}-\Delta_{M}=\left(1-c_{2}-c_{3}\right)^{2} J$. According to the equilibrium principle of Nash negotiation, the profit gap can be distributed by bargaining power, that is, the subsidy given by the retailer to the manufacturer should be $\Delta=(1-\mu)\left(\Delta_{R}-\Delta_{M}\right)=(1-\mu)^{3} J$. Similarly, when $\mu \in\left[0, \frac{1}{2}\right]$, the subsidy given by the manufacturer to the retailer is $\Delta=(1-\mu)\left(\Delta_{R}-\Delta_{M}\right)=(1-\mu)^{3} J$, we just consider the condition $\mu \in\left[\frac{1}{2}, 1\right]$ here. For this reason, when $\mu \in\left[\frac{1}{2}, 1\right]$, the manufacturer will get a total profit of $\overline{\bar{\Pi}}_{M}^{C}=$ $\Delta+\prod_{M}^{B}=(1-\mu)\left(2-2 \mu+\mu^{2}\right) J$, and the retailer will get a total profit of $\overline{\bar{\prod}}_{R}^{C}=\prod_{R}^{C}-\Delta=\left[\mu-(1-\mu)^{3}\right] J$, that is to say, the conclusion is proved.

Proposition 7 shows that although mode $C$ can achieve the optimal greenness coordination equivalent to the centralized control mode, there is a mode selection conflict between the retailer and the manufacturer under mode $C$. This study proposes to use the Nash negotiation equilibrium to modify this problem. Under the modified mode, the coordination between the greenness of the store 
brand product and the total profit of the supply chain can still be realized, which is equivalent to mode C. It also becomes a common dominant mode choice for the retailer and the manufacturer, which can eliminate the conflict between the retailer and the manufacturer in the selection of production mode.

\section{Numerical Example and Sensitivity Analysis}

\subsection{Numerical Example}

To illustrate the coordination effect of greenness of store brand product, the manufacturer's profit, the retailer's profit and total supply chain profit under the three production modes of A, B and C, we let $c_{1}=0.4, c_{2}=0.4, c_{3}=0.4$, and we take step length 0.01 , then we can get the optimal greenness curve, the optimal profit curve of each party and the optimal total profit curve of the supply chain in the retailer's negotiation strength interval $\mu \in[0,1]$ according to Equations (10)-(13). These curve graphs are shown in Figures 2-5.

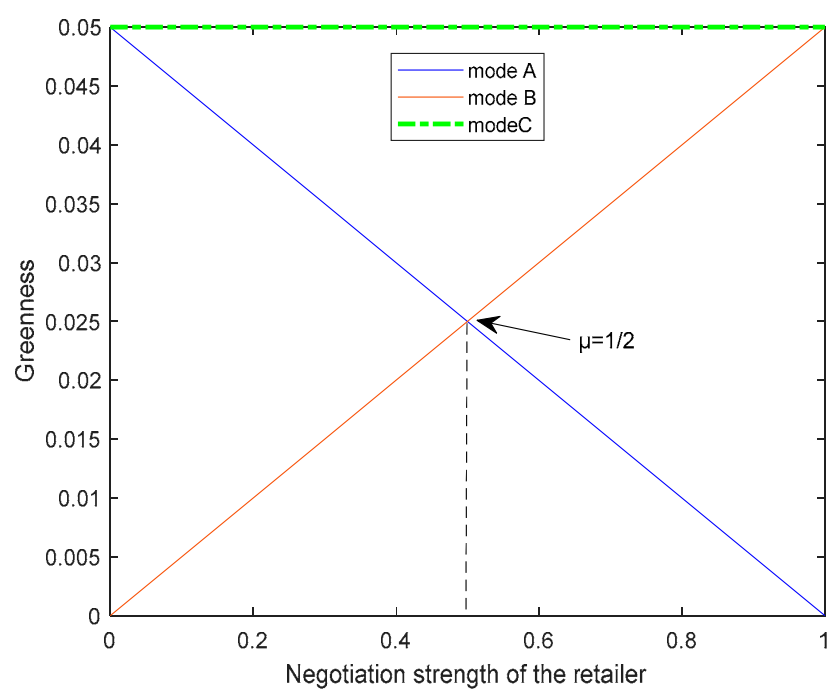

Figure 2. Curve of greenness.

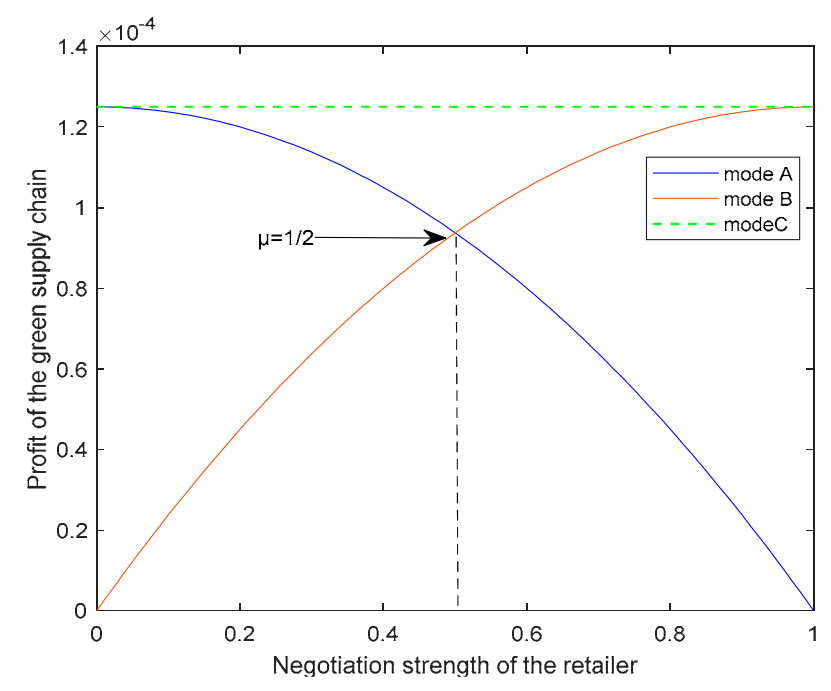

Figure 3. Curve of supply chain profit. 


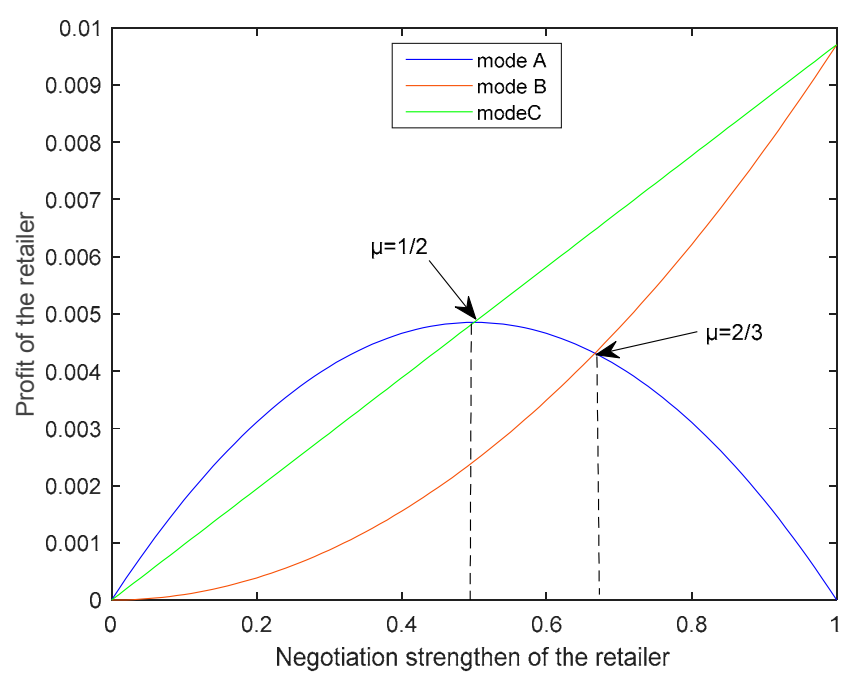

Figure 4. Curve of the retailer's profit.

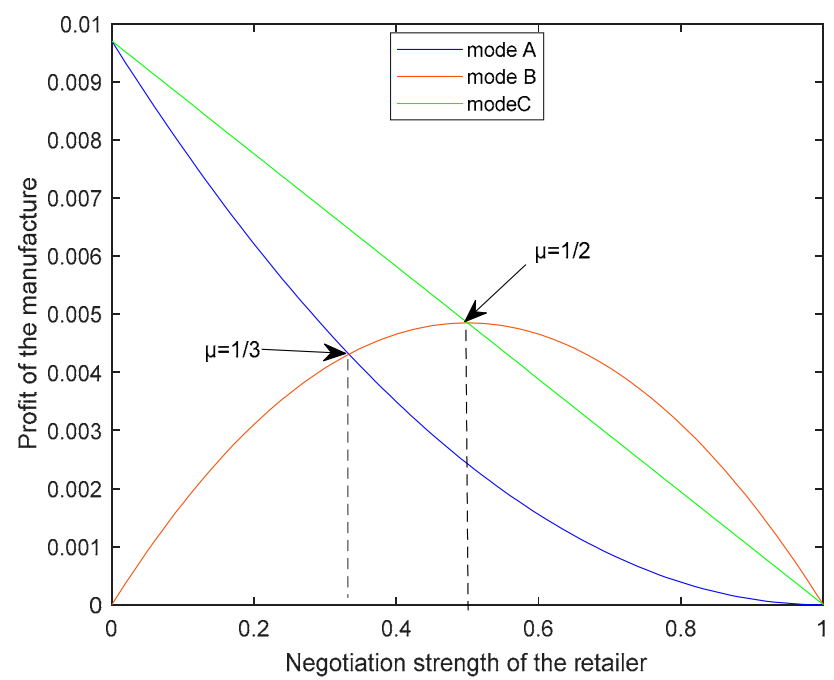

Figure 5. Curve of the manufacturer 's profit.

From Figures 2 and 3, we can see that:

(i) Under mode A, if the manufacturer undertakes all the initial one-off environmental investment in the early stage of the green product, the greenness of the retail store brand product and the total profit of the supply chain will decrease with the increase in the retailer's negotiation strength. This also means that under mode $\mathrm{A}$, the cost brought by the manufacturer's environmental investment will be greater than the profit, and the weaker position the manufacturer is in, the less willing it will be to invest in greenness, because the one-off environmental investment in the early stage may be held up.

(ii) Under mode B, if the retailer undertakes the initial one-off environmental investment in the early stage of the product, the greenness of the retail store brand product and the total profit of the supply chain will increase with the increase of the retailer's negotiation strength. With the enhancement of retailer's negotiation strength, although it may reduce the manufacturer's profit, the retailer will have enthusiasm for investing in greenness because the profit brought by the retailer's environmental investment will be greater than the cost, leading to an increase in the total profit of the supply chain. 
(iii) Comparing the greenness of product and the total profit of supply chain under mode A and mode $B$, we find that mode $A$ is better than mode $B$ when the negotiation strength of the retailer is in the interval $\mu \in[0,0.5]$, and mode $\mathrm{B}$ is better than mode $\mathrm{A}$ when the negotiation strength of the retailer is in the interval $\mu \in[0.5,1]$.

(iv) Under mode $C$, if the retailer and the manufacturer jointly undertake the initial one-off environmental investment in the early stage of product, the greenness and the total profit of supply chain are not related to the negotiation strength of the retailer, and the greenness and the total profit of supply chain are higher than that of mode A and mode B.

It can be seen from Figure 4 that the retailer's profit curve increases first and then decreases under mode A, increases all the time under modes B and C, and there is a turning point when the retailer's negotiation strength is 0.5 . When the retailer's negotiation strength is in the interval $\mu \in[0,0.5]$, the retailer chooses mode $\mathrm{A}$, which leads the manufacturer to undertake the initial one-off environmental investment in the early stage of the product with the highest profit. The reason for this is that the retailer is in a weak position at this time, the one-off environmental investment in the early stage of product will be held up, and the retailer is more willing to let the manufacturer undertake the risk of the investment. When $\mu \leq \frac{1}{2}$, mode $\mathrm{A}$ is the best choice and mode $\mathrm{C}$ is the suboptimal choice for the retailer. When $\frac{1}{2} \leq \mu \leq \frac{2}{3}$, for the retailer, although the profit of model A is lower than that of negotiation strength is 0.5 , it is still higher than that of model $\mathrm{B}$, Mode $\mathrm{C}$ is the best choice and mode $\mathrm{A}$ is the suboptimal choice. When $\frac{2}{3} \leq \mu \leq 1$, mode $C$ is the best choice and mode $B$ is the suboptimal choice. For this reason, mode $C$ is either the best choice or the suboptimal choice, and it is always not the worst choice in the whole optional space of $\mu \in[0,1]$ for the retailer. In the interval $\mu \in\left[\frac{1}{2}, 1\right]$, the profit of mode $A$ and mode $B$ is less than that of mode $C$ for the retailer, and the retailer will choose mode $C$ and jointly undertake the initial one-off environmental investment in the early stage of product together with the manufacturer.

It can be seen from Figure 5 that the manufacturer's profit curve first increases and then decreases under mode $\mathrm{B}$, and decreases all the time under mode $\mathrm{A}$ and mode $\mathrm{C}$. When $\mu \leq \frac{1}{2}$, for the manufacturer, the profit of mode $A$ and mode $B$ is less than that of mode $C$. The manufacturer will choose mode $C$, in which the retailer undertakes the one-off environmental investment in the early stage of the product together with the manufacturer. When $0 \leq \mu \leq \frac{1}{3}$, mode $\mathrm{C}$ is the best choice and mode $\mathrm{A}$ is the suboptimal choice for the manufacturer. When $\frac{1}{3} \leq \mu \leq \frac{1}{2}$, mode $C$ is the best choice and mode $B$ is the suboptimal choice for the manufacturer. When $\mu \geq \frac{1}{2}$, mode B is the best choice and mode $\mathrm{C}$ is the suboptimal choice for the manufacturer. Therefore, mode $C$ is either the best choice or the suboptimal choice and never the worst choice within the whole optional interval of $\mu \in[0,1]$ for the manufacturer.

Combining the analysis of Figures 4 and 5 , we can find that when $\mu \leq \frac{1}{2}$, the manufacturer is in a strong position, mode $\mathrm{C}$ is the best choice for the manufacturer and mode $\mathrm{A}$ is the best choice for the retailer. When $\frac{1}{2} \leq \mu \leq 1$, the retailer is in a strong position, mode $C$ is the best choice for the retailer, and mode $B$ is the best choice for the manufacturer. Therefore, there is a production mode choice conflict between the manufacturers and the retailer. However, considering that in the process of cooperation between the manufacturer and the retailer, the final choice of production mode is decided by the strong side, whether the negotiation strength of the retailer is greater than 0.5 or less than 0.5 , the result of joint decision-making of both sides is to choose $C$ mode. In combination with the analysis results of Figures 2 and 3 , mode $C$ can achieve the optimal coordination effect of greenness and total profit of supply chain through appropriate profit distribution. Therefore, mode $C$ is the optimal production mode of retail store brand green supply chain.

\subsection{Sensitivity Analysis}

To identify the contribution of each individual input in the model output, a sensitivity analysis was performed. This analysis provides information about how slight variations in input parameters like $c_{1}$, $c_{2}, c_{3}$ and $\mu$ can affect the model output, which in this study are profits of the retailer, the manufacture and the total supply chain and the greenness in different entrusted production modes. In this study, 
$\prod_{\mathrm{r}-\mathrm{a}}, \prod_{\mathrm{m}-\mathrm{a}}, \prod_{\mathrm{sc}-\mathrm{a}}$ represent the profit of the retailer, the manufacturer and the total supply chain, respectively, in mode $\mathrm{A}$, and $\theta_{\mathrm{a}}$ indicates the greenness in mode $\mathrm{A}$. They do the same in the $\mathrm{B}$ and $\mathrm{C}$ modes. This study uses the Monte Carlo Simulation method to randomly generate parameter values from 0 to 1 . The effects of the parameter on output variables were assessed, and the results are shown in Figure 6. It may be observed that the sensitive parameters for output variables were completely different.
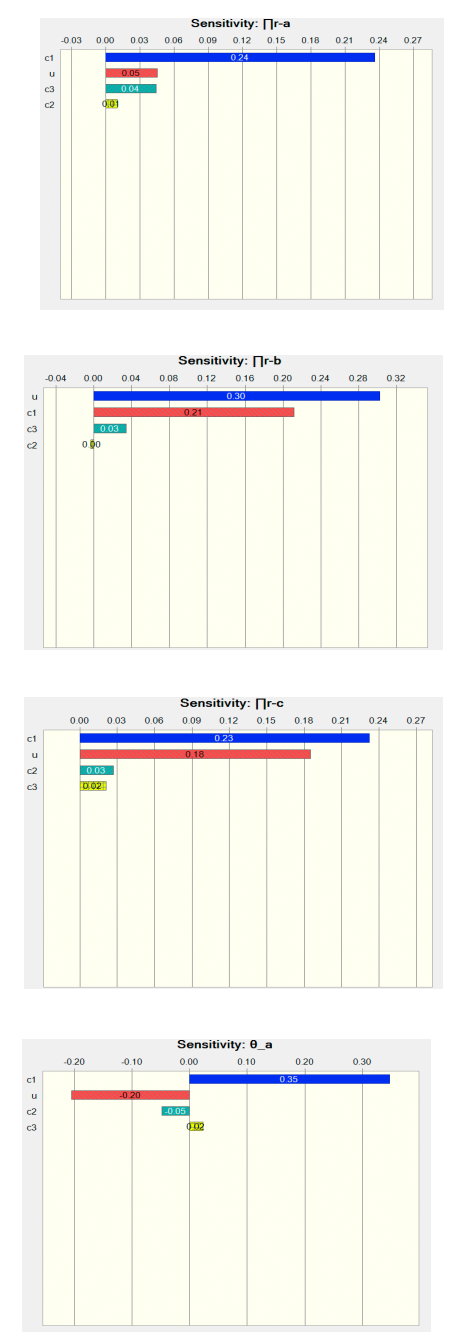
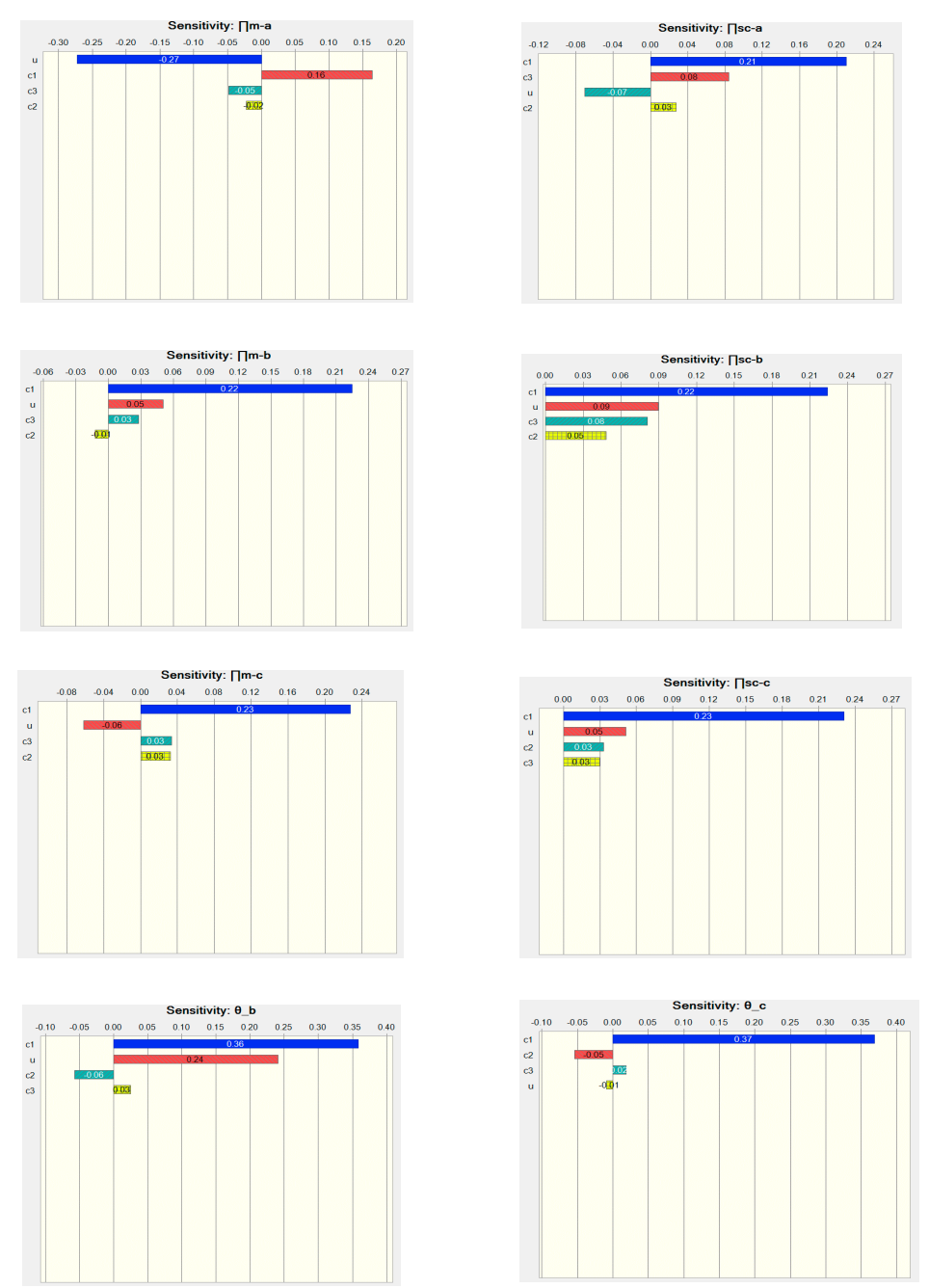

Figure 6. Parameter sensitivity analysis.

This study calculates sensitivity by computing rank correlation coefficients between every parameter and every output variable while the simulation is running 1000 trials. The larger the absolute value of the correlation coefficient, the stronger the relationship. For example, in mode $\mathrm{A}, c_{1}$ has the largest correlation coefficient $(0.24)$ with retailer's profit $\prod_{\mathrm{r}-\mathrm{a}}$, followed by $\mu(0.05), c_{3}(0.04)$, and $c_{2}$ (0.01). Hence, the retailer should first focus on the fixed cost of one-off environmental investment in the early stage of green product to improve profit. Meanwhile, in mode B, the rank correlation coefficients between the four parameters and profit of the retailer has changed, namely, $\mu(0.30), c_{1}(0.21)$, $c_{3}(0.03), c_{2}(0.001)$. Therefore, the retailer should adjust its negotiation strength in this mode. Generally, the result of sensitivity analysis allows the decision-maker to identify the input parameters that affect the output most and prioritize them in the decision-making. 


\section{Results and Discussion}

Through comparative analysis of three production modes of green supply chain coordination of the retail store brand product: OEM mode (mode A), full participation mode (mode B), and partial participation mode (mode $\mathrm{C}$ ), we can reach the following results:

(i) OEM mode (mode A) is the best choice for the retailer when it is in a weak position, but it is not the best choice for the manufacturer. The reason is that direct OEM can reduce the risk of the retailer but can increase the hold-up risk of the manufacturer's investment under mode A. Under the OEM mode, although it can increase the retailer's profit, it will squeeze the manufacturer's profit with the increase of retailer's negotiation strength, and it will also lead to the decrease of the product's greenness and the total profit of the whole supply chain, which cannot achieve the best coordination effect. When the negotiation strength of the retailer is in a strong position, the profit of the retailer and the manufacturer will decrease under the direct OEM mode, which has the double decreasing effect of marginal profit. Therefore, when the retailer is in a strong position, the direct OEM production mode is neither the best choice of the retailer nor the best choice of the manufacturer.

(ii) The retailer's full participation mode (mode B) is the best choice for the manufacturer when the retailer is in a strong position, but it is not the best choice for the retailer. The reason for this is that the retailer fully undertakes the initial one-off environmental investment in the early stage under mode $B$, although it can reduce the risk of the manufacturer, but it can increase the investment risk of the retailer. Under mode B, when the retailer is in a strong position, although the retailer's negotiation strength can increase the retailer's profit and squeeze part of the manufacturer's profit, the retailer is still willing to choose mode $C$, so the manufacturer can jointly undertake the risk brought by the one-off environmental investment in the early stage. When the retailer is in a weak position, the retailer's full participation mode is neither the best choice for the retailer nor the best choice for the manufacturer.

(iii) The retailer's partial participation mode (mode C) in the whole optional range of retailer's negotiation strength $\mu \in[0,1]$ is either the best choice or the suboptimal choice for both partners, and is never the worst choice. When the retailer is in a weak position and the manufacturer is in a strong position, the partial participation mode is the best choice for the manufacturer. When the retailer is in a strong position and the manufacturer is in a weak position, the partial participation mode is the best choice for the retailer. Considering that the mode choice for both sides of green supply chain cooperation is determined by the strong side, the retailer's partial participation mode will become the common choice of both sides.

(iv) From the perspective of coordination effect, the greenness and profit of the total supply chain are exactly the same as those of centralized control under the retailer's partial participation mode, and it can achieve the best coordination effect of green supply chain. This is because the retailer and the manufacturer share the burden of the initial one-off environmental investment in the early stage, and it can share investment risk and improve the enthusiasm of environmental investment. In addition, the greenness and the total profit of the supply chain are not related to the negotiation strength of the retailer, and these are related to the initial one-off environmental input cost coefficient, marginal production cost coefficient and sales cost coefficient under the partial participation mode. Therefore, no matter how high the negotiation strength of the retailer is, the green supply chain should choose the partial participation mode of the retailer, and the initial one-off environmental investment should be jointly undertaken by the retailer and the manufacturer. 


\section{Conclusions and Limitations}

\subsection{Conclusion}

Taking the shift of negotiation strength of the manufacturer and the retailer, the three different entrusted production modes, and the mechanism of subsidy into consideration, this study obtains equilibrium solutions under three decision-making scenarios and some valuable conclusions. In short, this paper reveals how both parties' negotiation strengths provide for the manufacturer and retailer to simultaneously affect the optimal product greenness, both parties' profit, and the green supply chain total profit. Meanwhile, this paper also reveals the impact of retailers' negotiation strength on the equilibrium solutions in the context of subsidy. In addition, this paper also explores the specific impact of parameter variations on the research results through sensitivity analysis, which provides practical reference for green supply chain decision makers. To better demonstrate the research contribution of this article, here we will answer the questions raised above.

(1) Under different entrusted production modes, what effect does the retailer's relative negotiation strength make on product greenness, retailer profit, manufacturer profit and total supply chain profit?

In mode $\mathrm{A}$, when the negotiation strength of retailers is in a weak position $\mu \in[0,0.5]$, although the increase in the retailer's negotiation strength can increase its profit, it will reduce the manufacturer's profit and enthusiasm for the initial one-off environmental investment. However, when the retailer's bargaining power is further enhanced and exceeds 0.5 , both the retailer's and the manufacturer's profit will decrease with the increase of the retailer's bargaining power, which leads to the problem of diminishing double marginal profit of all partners. Additionally, after the negotiation strength of retailers exceeds the threshold of 0.5 , it is not beneficial for the retailer to improve the greenness of store brand products and the total profit of supply chain.

In mode $B$, when the retailer's negotiation strength is in the interval $\mu \in[0,0.5]$, the manufacturer's optimal profit is the increasing function of the retailer's negotiation strength; when the retailer's negotiation strength is in the interval $\mu \in[0.5,1]$, the manufacturer's optimal profit is the decreasing function of the retailer's negotiation strength. However, no matter what the retailer's negotiation strength is, the greenness of the retail store brand product and the total profit of the supply chain will increase.

In mode $C$, the retailer's optimal profit is the increasing function of its negotiation strength, and the manufacturer's optimal profit is the decreasing function of the retailer's negotiation strength. However, the optimal greenness of product and the optimal total profit of supply chain are not related to the negotiation strength of the retailer.

(2) Which mode can achieve the optimal coordination mode of green supply chain among the three different entrusted production modes?

From the perspective of coordination effect, the greenness and the profit of total supply chain are exactly the same as those of centralized control under the retailer's partial participation mode (Mode C), and it can achieve the best coordination effect of green supply chain. This is because the retailers and the manufacturer share the burden of the initial one-off environmental investment in the early stage, and it can share investment risk and improve the enthusiasm of environmental investment. In addition, the greenness and the total profit of the supply chain are not related to the negotiation strength of the retailer, and they are related to the initial one-off environmental input cost coefficient, marginal production cost coefficient, and sales cost coefficient under the partial participation mode. Therefore, no matter how negotiation strength the retailer is, the green supply chain should choose the partial participation mode of the retailer, and the initial one-off environmental investment should be jointly undertaken by the retailer and the manufacturer.

Our conclusions in this paper have some differences with respect to existing studies. Firstly, this paper differs from existing studies that conclude that the retailer's and the manufacturer's relative 
negotiation strength can influence the selection of entrusted production mode in green supply chain, while Zhang et al. (2014) [40] showed that different production costs will have an impact on the choice of production modes by manufacturers when consumers have different valuations of the products in supply chain. Secondly, unlike the conclusions of existing studies suggesting that the greenness of the product is affected by factors such as supply chain structures, the green product types, and the types of competition (price competition and greenness competition) (Zhu and He, 2017) [43], this paper shows that the choice of entrusted production mode can affect the greenness, while the greenness is not related to the initial one-off environmental input cost coefficient, marginal production cost coefficient and sales cost coefficient.

\subsection{Limitations and Future Work}

Since there is little literature introducing the retailer's negotiation strength into decision-making research with respect to the green supply chain, this study enriches this research content and explores the impact of the three different entrusted production modes of store brand products, which can provide a reference for stakeholders (i.e., manufactures and retailers) in a green supply chain in adopting reasonable strategies. However, this study nonetheless has some limitations. Firstly, in order to simplify the model, this paper only considers one retailer and one manufacturer in the supply chain. In fact, there may be multiple participants that affect profit of all supply chain parties. Secondly, this study only explores the impact of retailer negotiation strength on supply chain stakeholders, ignoring the impact of third parties, such as consumer demand preferences on product greenness and green supply chain. In addition, the manufacturer and the retailer have opportunistic behavior in the process of green investment due to information asymmetry, this paper overlooks the problem of information asymmetry. For this reason, future research could consider the influence of the retailer's negotiation strength on the profits of supply chain participants and the greenness of products by adding factors such as consumer demand preference and information asymmetry in the case of multiple manufacturers and retailers.

Author Contributions: S.W. (Shaobo Wu) and S.W. (Shiping Wen) conceived and designed the study, Q.Z. completed the paper in English, X.Q. gave many research advices and revised the manuscript. All authors have read and agreed to the published version of the manuscript.

Funding: This research was supported by the project "On decision and model of online shopping supply chain extension based on product reliability and customer service expectation" (Project No. 71802031), the project of the Ministry of Education's Humanity and Social Sciences Research "On the evolution and early warning mechanism of uncertain network public opinion"(No. 19YJAZH044), the project of Basic Research and Frontier exploration of Chongqing Natural Science Foundation "On the competition decision and optimization of 3C products online channel of home appliances under the perspective of customer driven" (No. cstc2018jcyjAX0801), the project of China's National Social Science Fund Project "Research on the construction of innovation ecosystem and the mechanism of coordinated development of emerging industries in China during the transformation period" (No. 17BGL018) and the project of China Postdoctoral Science Foundation "Decision-making for extending warranty of competitive online shopping supply chain based on brand reputation and product reliability" (No. 2019M663483).

Conflicts of Interest: The authors declare no conflict of interest.

\section{References}

1. Huang, Z.; Li, S.X.; Mahajan, V. An analysis of manufacturer-retailer supply chain coordination in cooperative advertising. Decis. Sci. 2002, 33, 469-494. [CrossRef]

2. Koskinen, S. UK private label: European brand leader? Eur. Retail Dig. 1999, 11, 5-8.

3. Berges-Sennou, F. Store loyalty, bargaining power and the private label production issue. Eur. Rev. Agric. Econ. 2006, 33, 315-335. [CrossRef]

4. Bergès, F.; Bouamra-Mechemache, Z. Is producing a private label counterproductive for a branded manufacturer? Eur. Rev. Agric. Econ. 2012, 39, 213-239. [CrossRef]

5. Wang, K.; Zhao, Y.; Cheng, Y.; Choi, T.-M. Cooperation or competition? Channel choice for a remanufacturing fashion supply chain with government subsidy. Sustainability 2014, 6, 7292-7310. [CrossRef] 
6. Ingene, C.A.; Parry, M.E. Channel coordination when retailers compete. Mark. Sci. 1995, 14, 360-377. [CrossRef]

7. Choi, S.C. Price competition in a channel structure with a common retailer. Mark. Sci. 1991, 10, $271-296$. [CrossRef]

8. Krishnan, T.V.; Soni, H. Guaranteed profit margins: A demonstration of retailer power. Int. J. Res. Mark. 1997, 14, 35-56. [CrossRef]

9. Bernstein, F.; Nagarajan, M. Competition and cooperative bargaining models in supply chains. Found. Trends ${ }^{\circledR}$ Technol. Inf. Oper. Manag. 2012, 5, 87-145.

10. Curkovic, S.; Sroufe, R. Using ISO 14001 to promote a sustainable supply chain strategy. Bus. Strateg. Environ. 2011, 20, 71-93. [CrossRef]

11. Zimon, D.; Madzík, P. Standardized management systems and risk management in the supply chain. Int. J. Qual. Reliab. Manag. 2019, 37, 305-327. [CrossRef]

12. Zimon, D.; Madzik, P. Impact of Implementing ISO 14001 Standard Requirements for Sustainable Supply Chain Management in the Textile Industry. Fibres Text. East. Eur. 2019, 27, 8-14. [CrossRef]

13. Zimon, D.; Tyan, J.; Sroufe, R. Implementing Sustainable Supply Chain Management: Reactive, Cooperative, and Dynamic Models. Sustainability 2019, 11, 7227. [CrossRef]

14. Richardson, P.S.; Dick, A.S.; Jain, A.K. Extrinsic and intrinsic cue effects on perceptions of store brand quality. J. Mark. 1994, 58, 28-36. [CrossRef]

15. Collins-Dodd, C.; Lindley, T. Store brands and retail differentiation: The influence of store image and store brand attitude on store own brand perceptions. J. Retail. Consum. Serv. 2003, 10, 345-352. [CrossRef]

16. Steenkamp, J.-B.E.M.; Van Heerde, H.J.; Geyskens, I. What makes consumers willing to pay a price premium for national brands over private labels? J. Mark. Res. 2010, 47, 1011-1024. [CrossRef]

17. Keller, K.O.; Dekimpe, M.G.; Geyskens, I. Let your banner wave? Antecedents and performance implications of retailers' private-label branding strategies. J. Mark. 2016, 80, 1-19. [CrossRef]

18. Cuneo, A.; Milberg, S.J.; del Carmen Alarcon-del-Amo, M.; Lopez-Belbeze, P. Private label and manufacturer brand choice in a new competitive reality: Strategic directions and the future of brands. Eur. Manag. J. 2019, 37, 117-128. [CrossRef]

19. Mills, D.E. Why retailers sell private labels. J. Econ. Manag. Strateg. 1995, 4, 509-528. [CrossRef]

20. Choi, S.C.; Coughlan, A.T. Private label positioning: Quality versus feature differentiation from the national brand. J. Retail. 2006, 82, 79-93. [CrossRef]

21. Ru, J.; Shi, R.; Zhang, J. Does a store brand always hurt the manufacturer of a competing national brand? Prod. Oper. Manag. 2015, 24, 272-286. [CrossRef]

22. Jin, Y.; $\mathrm{Wu}, \mathrm{X}$; $\mathrm{Hu}, \mathrm{Q}$. Interaction between channel strategy and store brand decisions. Eur. J. Oper. Res. 2017, 256, 911-923. [CrossRef]

23. Li, H.; Leng, K.; Qing, Q.; Zhu, S.X. Strategic interplay between store brand introduction and online direct channel introduction. Transp. Res. Part E Logist. Transp. Rev. 2018, 118, 272-290. [CrossRef]

24. Chambolle, C.; Christin, C.; Meunier, G. Optimal production channel for private labels: Too much or too little innovation? J. Econ. Manag. Strateg. 2015, 24, 348-368. [CrossRef]

25. Ma, W.; Cheng, R.; Ke, H.; Zhang, J. Store-Brand Production Arrangement Based on the Game Theory. Math. Probl. Eng. 2018, 2018, 1-10. [CrossRef]

26. Liao, B.; Yano, C.A.; Trivedi, M. Optimizing Store-Brand Quality: Impact of Choice of Producer and Channel Price Leadership. Prod. Oper. Manag. 2020, 29, 118-137. [CrossRef]

27. Wu, G.D.; Tang, D.Z. Inter-organizational cooperative innovation of project-based supply chains under consideration of monitoring signals. Int. J. Simul. Model 2015, 14, 539-550. [CrossRef]

28. Wu, G.-D. Project-based supply chain cooperative incentive based on reciprocity preference. Int. J. Simul. Model 2014, 13, 102-116. [CrossRef]

29. Pagell, M.; Shevchenko, A. Why research in sustainable supply chain management should have no future. J. Supply Chain Manag. 2014, 50, 44-55. [CrossRef]

30. Svensson, G. Aspects of sustainable supply chain management (SSCM): Conceptual framework and empirical example. Supply Chain Manag. An. Int. J. 2007, 12, 262-266. [CrossRef]

31. Chatterjee, K.; Kar, S. An Induced Fuzzy Rasch-VIKOR model for Warehouse Location evaluation under Risky Supply chain. In Proceedings of the International Conference on Pattern Recognition and Machine Intelligence, Berlin, Germany, 10-14 December 2013; pp. 714-719. 
32. Chatterjee, K.; Kar, S. Multi-criteria analysis of supply chain risk management using interval valued fuzzy TOPSIS. Opsearch 2016, 53, 474-499. [CrossRef]

33. de Oliveira, U.R.; Espindola, L.S.; da Silva, I.R.; da Silva, I.N.; Rocha, H.M. A systematic literature review on green supply chain management: Research implications and future perspectives. J. Clean. Prod. 2018, 187, 537-561. [CrossRef]

34. Jayaram, J.; Avittathur, B. Green supply chains: A perspective from an emerging economy. Int. J. Prod. Econ. 2015, 164, 234-244. [CrossRef]

35. Singh, A.; Kar, S.; Pamucar, D. Stakeholder role for developing a conceptual framework of sustainability in organization. Sustainability 2019, 11, 208. [CrossRef]

36. Rebs, T.; Brandenburg, M.; Seuring, S. System dynamics modeling for sustainable supply chain management: A literature review and systems thinking approach. J. Clean. Prod. 2019, 208, 1265-1280. [CrossRef]

37. Gosling, J.; Jia, F.; Gong, Y.; Brown, S. The role of supply chain leadership in the learning of sustainable practice: Toward an integrated framework. J. Clean. Prod. 2016, 137, 1458-1469. [CrossRef]

38. Zhao, R.; Neighbour, G.; Han, J.; McGuire, M.; Deutz, P. Using game theory to describe strategy selection for environmental risk and carbon emissions reduction in the green supply chain. J. Loss Prev. Process Ind. 2012, 25, 927-936. [CrossRef]

39. Zhang, C.-T.; Liu, L.-P. Research on coordination mechanism in three-level green supply chain under non-cooperative game. Appl. Math. Model. 2013, 37, 3369-3379. [CrossRef]

40. Zhang, C.-T.; Wang, H.-X.; Ren, M.-L. Research on pricing and coordination strategy of green supply chain under hybrid production mode. Comput. Ind. Eng. 2014, 72, 24-31. [CrossRef]

41. Chatterjee, K.; Zavadskas, E.K.; Roy, J.; Kar, S. Performance evaluation of green supply chain management using the grey DEMATEL-ARAS Model. In Proceedings of the International Conference on Frontiers in Optimization: Theory and Applications; Springer: Berlin, Germany, 2016; pp. 347-363.

42. Chatterjee, K.; Pamucar, D.; Zavadskas, E.K. Evaluating the performance of suppliers based on using the R'AMATEL-MAIRCA method for green supply chain implementation in electronics industry. J. Clean. Prod. 2018, 184, 101-129. [CrossRef]

43. Zhu, W.; He, Y. Green product design in supply chains under competition. Eur. J. Oper. Res. 2017, 258, 165-180. [CrossRef]

44. Liu, P.; Yi, S. Pricing policies of green supply chain considering targeted advertising and product green degree in the Big Data environment. J. Clean. Prod. 2017, 164, 1614-1622. [CrossRef]

45. Wei, J.; Wang, W.; Tsai, S.-B.; Yang, X. To Cooperate or Not? An Analysis of Complementary Product Pricing in Green Supply Chain. Sustainability 2018, 10, 1392. [CrossRef]

46. Tang, X.; Wei, G. Models for green supplier selection in green supply chain management with Pythagorean 2-tuple linguistic information. IEEE Access 2018, 6, 18042-18060. [CrossRef]

47. Hong, Z.; Guo, X. Green product supply chain contracts considering environmental responsibilities. Omega 2019, 83, 155-166. [CrossRef]

48. Chen, D.; Ignatius, J.; Sun, D.; Goh, M.; Zhan, S. Pricing and equity in cross-regional green supply chains. Eur. J. Oper. Res. 2020, 280, 970-987. [CrossRef]

49. Sarkar, S.; Bhadouriya, A. Manufacturer competition and collusion in a two-echelon green supply chain with production trade-off between non-green and green quality. J. Clean. Prod. 2020, 253, 119904. [CrossRef]

50. Shan, H.; Zhang, C.; Wei, G. Bundling or Unbundling? Pricing Strategy for Complementary Products in a Green Supply Chain. Sustainability 2020, 12, 1331. [CrossRef]

51. Li, S.; Qiao, J.; Cui, H.; Wang, S. Realizing the Environmental Benefits of Proactive Environmental Strategy: The Roles of Green Supply Chain Integration and Relational Capability. Sustainability 2020, 12, 2907. [CrossRef]

52. Su, C.; Liu, X.; Du, W. Green Supply Chain Decisions Considering Consumers' Low-Carbon Awareness under Different Government Subsidies. Sustainability 2020, 12, 2281. [CrossRef]

53. Balachandran, K.R.; Radhakrishnan, S. Quality implications of warranties in a supply chain. Manag. Sci. 2005, 51, 1266-1277. [CrossRef]

54. Hsieh, C.-C.; Liu, Y.-T. Quality investment and inspection policy in a supplier-manufacturer supply chain. Eur. J. Oper. Res. 2010, 202, 717-729. [CrossRef]

55. Jiang, L.; Guo, Y.; Su, J.; Jian, J.; He, Y. Sub-Coordination in a Competing Supply Chain With a 3PL Provider. IEEE Access 2019, 7, 158148-158159. [CrossRef] 
56. Chao, G.H.; Iravani, S.M.R.; Savaskan, R.C. Quality improvement incentives and product recall cost sharing contracts. Manag. Sci. 2009, 55, 1122-1138. [CrossRef]

57. Zhu, K.; Zhang, R.Q.; Tsung, F. Pushing quality improvement along supply chains. Manag. Sci. 2007, 53, 421-436. [CrossRef]

58. Battigalli, P.; Fumagalli, C.; Polo, M. Buyer power and quality improvements. Res. Econ. 2007, 61, 45-61. [CrossRef]

(C) 2020 by the authors. Licensee MDPI, Basel, Switzerland. This article is an open access article distributed under the terms and conditions of the Creative Commons Attribution (CC BY) license (http://creativecommons.org/licenses/by/4.0/). 